\title{
LA EXPERIENCIA ARGENTINA DE MONITOREAR PUBLICAMENTE LOS PRECIOS EN SUPERMERCADOS
}

Por Anett Erdmann, Académica FEN UAH. Ph.D. en Economia, Universidad Carlos III de Madrid, España

Desde el 13 de mayo de este año, entró en funcionamiento el "Sistema Electrónico de proyecto gubernamental en el que a través de la plataforma online www reciosclars. gob.ar y la mobile "App Control de Precios Claros (CdP)" los usuarios pueden comparar los precios y promociones disponibles en los supermercados más cercanos a ubicación donde consumen. La resolución 12/2016 formaliza al SEPA y motiva este proyecto con el proposito de facilitar a los consumidores el acceso a una "información amplia, cierta, clara, veraz y detallada de los precios vigentes. EI SEPA es un medio de in-

pra online y obliga todos los concos que realicen venta minorista de productos de consumo masivo a reportar diariamente tipo de bonificaciones en cada punto de venta para una gran lista de productos específicos. Mientras la resolución hace énfasis en la motivación de proporcionar una mayor transparencia de precios de cara al consumidor, el objetivo destacado por los medios de comunicación es combatir el problem de la inflación. ("Contra la inflación, llegó SEPA", La Nación, 15 de febrero 2016) Es importante destacar que una diferencia respecto a proyectos gubernamentales anteriores de la publicacion de precios nivel de sucursales de supermercados (que actualización a nivel diario de los datos y los medios de información proporcionados consumidor, lo que lo convierte en una potencial herramienta de decisión de compra Desde abril de este año, Uruguay está adaptando su propio "Sistema de Información de Precios al Consumidor" (SIPC) creando un registro de establecimientos obligados a reportar precios (Decreto 106/016) recon-

vación; cambió la periodicidad de la publicación de precios de mensual o quincenal los consumidores - además de y facilitó web - una App para el móvil (PreciosGub) que fue lanzada justo antes del cierre de esta edición para una muestra de establecimientos que figuraban en vers teriores del SIP.

Si estos proyectos tuvieran un impacto significativo sobre la competencia entre los supermercados y por to tanto sobre los precios de consumo, serian interesante para cualquier economia, por lo que analigenera.

El beneficio potencial de una plataforma pulitica con la informacion de precios es fado una presión competitiva entre empresas y como consecuencia una reducción de precios. Si analizamos la situación, podemos diferenciar dos tipos de consumidores: los consumidores activos que comparan precios antes de tomar la decisión de comprar y los consumidores inactivos que van al supermercado mas cercano o de Conforar precios. A cual de estos grupos pertenece un consumidor depende de su valoración del tiempo, costos miento de productos entre otros facenata puesta en matcha de SEPA implica los costos de bisqueda disminum para todos los consumidores lo que -a corto plazo- puede llevar a una competencia más intensa a través de dos efectos: El primero, aumentando las opciones para los consumidores que antes comparaban los precios de algunos supermercados y que ahora tienen más alternativas a considerar ya que antes compitiendo por dicho segmento. E segundo efecto es facilitar el seguimiento de los precios a un costo nulo o, en pocos clicks, a algunos consumidores que convirtiéndolos en compradores activos Esto implica que las empresas compitan por una fracción mayor de consumidores, lo que ejerce adicionalmente presión sobre los precios.

Hasta acá todo es positivo para el consumidor. Sin embargo, el cambio en la estructura de la información del mercado que implica el SEPA tiene más consecuencias. Primero, no se consideran otros atributos que no sea el precio del producto embargo representarmercado y que sin midor tos productos de los supel condos son altamente diferenciados $y$ existen muchos otros atributos valorados por los consumidores: su calidad, frescura, proposición de inventario, la variedad de productos, la presentación de estos en la tienda el servicio, la limpieza, la disponibilidad de intos, la política de devolución c. Todos los atributos mencionados pueen ser considerados medidas de calidad teries enciase por "precios bajos todos los dias" "precios promocionales"- están vinculadas

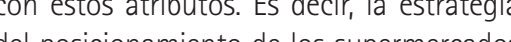
es un "parume" De de los supermercados ens dónde comprar unicanente sobre formación pública las consecuencias a largo plazo de reportar los precios y la geolocalización de los supermercados será que os que venden productos de calidad baja se beneficiarán con la falta de información sobre otros atributos del producto, mienas que los supermercados con productos erán ventas. un cambio en los incentivos de los super-
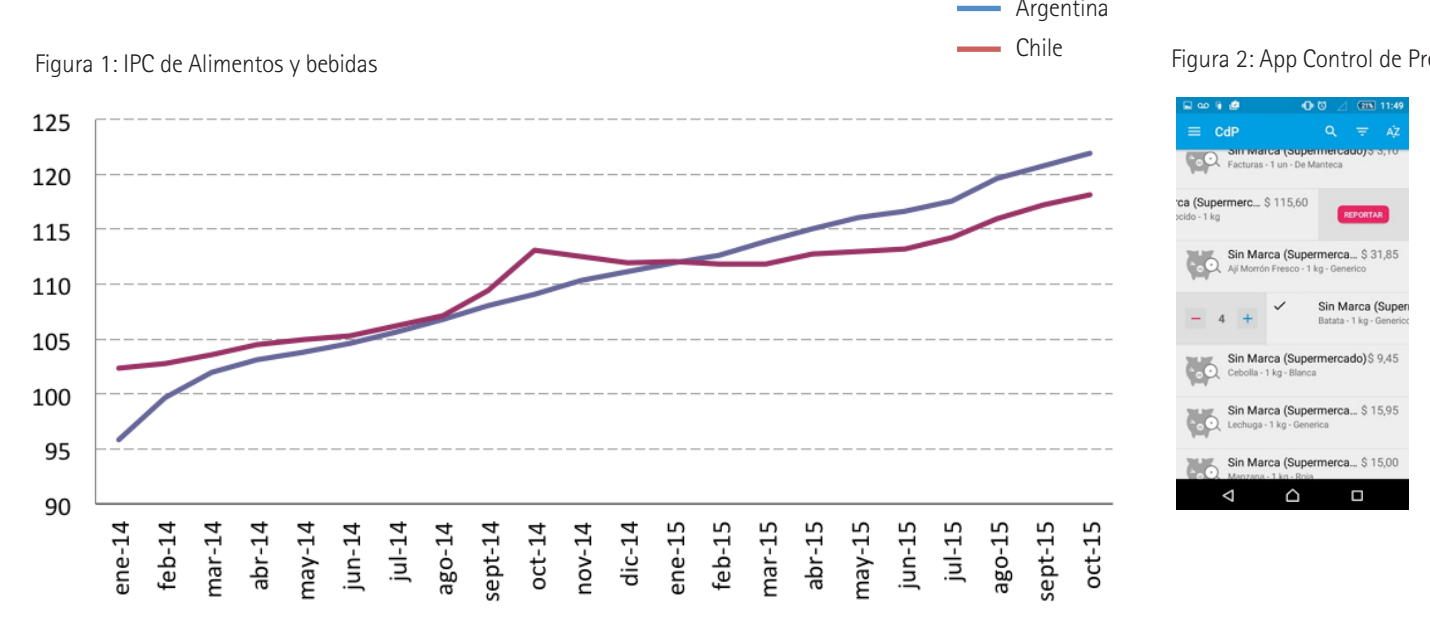

atos: INE Chile e INDEC Argent

mercados hacía una calidad peor, es decir, "no hay incentivo a invertir en atributos consumidor a basar su decisión de compra principalmente en el precio del producto. Este fue uno de los argumentos para retirar un sistema similar que se implantó en España en 2009. Con el objetivo de aumentar la transparencia e información de los consumidores, se creó el "Observatorio de Precios" en el cual se publicaban trimestramente indices de precios de supermercados observados en una muestra de sucursales (no reportados por las empresas como el SEPA). La plataforma web causo criticas dos ya que a varte dólo los precios y a calidad de los productos, la información era para basar la decisión de compra en un supermercado o en otro Finalmente, con cambio de Gobierno, el proyecto se cancelo en 2011 y se retiraron los datos de la web. Por lo tanto, si se confirmara el uso masvo del SEPA por parte de los consumidores como herramienta de decisión de compra, seria recomendable mejorar el sistema incluyendo valoraciones de calidad de los propios supermercados y los productos. Segundo, al publicar los precios de articulos de valor clave, la comparación de precios

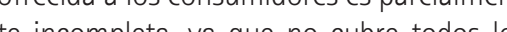

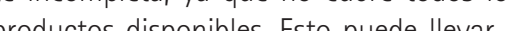
una competencia enfocada en los productos claves que puede compensarse elevando los precios de otros artículos.

Tercero, hay que considerar los costos adicionales que supone la publicación de precios para los supermercados. Uno de los argumentos de aplazar el proyecto una

y otra vez fueron los problemas por parte de las empresas para implementarlo ya que tuvieron que crear o reorganizar puestos de trabajo para poder cumplir con su deber de reportar los precios todos los dias. Si los supermercados repercuten parcial o totalmente estos costos adicionales a los consumidores
de sus precio

Además es inportante reconocer que el SEPA no solo aumenta la transparencia para los consumidores, sino también para los supermercados, las autoridades de competencia y terceros. Por un lado, la transpaentre las empresas, lo que se ha visto en otras industrias. Por otro lado, facilita a las autoridades de competencia la supervisión de posibles prácticas anticompetitivas. Por último, también proporciona una amplia base de datos para los investigadores y la

En el corto plazo el efecto neto de SEPA podria llevar a la presión deseada sobre los precios de compra, pero los cambios en los incentivos para las empresas podrian llevar a resultados desfavorablespara los consumidores. Por ello sistema para productos no ide este

YY SI FUEPA APUCADO A UNA INDUSTRA CON PRODUCTOS HOMOGÉNEOS?

Un claro ejemplo de referencia es el merderado homogéneo, no sólo por las mismas caracteristicas de un cierto tipo de gasolina (lo que no se puede decir de muchos de los productos que venden los supermercados sino también porque los consumidores van a una gasolinera a comprar gasolina en el caso de los supermercados!. Dado los pocos tipos de gasolina ofrecidos, a tas gasolineras no les resulta dificil informarse sobre los precios de los competidores -con sin obligación de publicar los precios. las calidad, productos no listados y costos de implementación no son relevantes 政 作 作 cones de Servicios" que existe en Chile es Pestos de Jusqueda para algunos consumidores y cos a latoridades competencia para supervisar las prácticas del sector.

Finalmente, es necesario considerar que una misma politica aplicada sobre industrias que se diferencian en el tipo de bienes (productos idénticos o diferenciados), la es e los consumidores puede tener distintos festos sobre las acciones estrategicas de las empresas. En el caso del SEPA, el tiempo competencia entre los supermercados en Argentina.

Decano: Jorge Rodríguez

e-mail: jrodrigu@uahurtado. 